\title{
Surveying Geology Concepts In Education Standards For A Rapidly Changing Global Context
}

Sarah K. Guffey, University of Wyoming, USA

Stephanie J. Slater, Ph.D., CAPER Center for Astronomy \& Physics Education Research, USA

Sharon P. Schleigh, Ed.D., East Carolina University, USA

Timothy F. Slater, Ph.D., University of Wyoming, USA

Inge Heyer, Ph.D., Loyola University Maryland, USA

\begin{abstract}
Internationally much attention is being paid to which of a seemingly endless list of scientific concepts should be taught to schoolchildren to enable them to best participate in the global economy of the $21^{\text {st }}$ Century. In regards to science education, the concepts framing the subject of geology holds exalted status as core scientific principles in the Earth and space sciences domain across the globe. Economic geology plays a critical role in the global economy, historical geology guides research into predictions related by global climate change, and environmental geology helps policy makers understand the impact of human enterprises on the land, among many other geological sciences-laden domains. Such a situation begs the question of which geology concepts are being advocated in schools. Within the U.S. where there is no nationally adopted curriculum, careful comparative analysis reveals surprisingly little consensus among policy makers and education reform advocates about which geology concepts, if any, should be included in the curriculum. This lack of consensus manifests itself in few traditional or modern geology concepts being taught to U.S. school children.
\end{abstract}

Keywords: Geosciences Education; Geocognition; Science Education Standards

\section{INTRODUCTION}

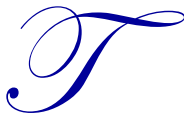

here is considerable investment throughout the international community to ensure that all citizens obtain the skills and knowledge necessary to participate in the global economy. An essential aspect of ensuring access to global resources and opportunities includes effective education in science, technology, engineering, and mathematics (STEM) at the primary and secondary levels. Individual nations and local school settings will naturally tailor educational objectives and instructional methods to serve their regional needs, transmit cultural values, and leverage available resources. However, equitable access suggests that all students in all settings should have the opportunity to learn the same basic core scientific content. Carefully identifying that core STEM scientific content to be learned is a monumental task, of concern to every nation.

In the scope of the science that pre-college students should master, the domain of geology encompasses many scientific concepts that are of global significance. By definition, geology is the study of Earth, the materials of which it is made, the structure of those materials, and the processes acting upon them. Geology is the study of how Earth's materials, structures, processes, and organisms have changed over time. The major concepts in geology include Earth's systems, plate tectonics, geologic time, Earth's structure, Earth's minerals, fossils, landforms, processes that shape the earth, weathering and erosion, radioactivity, rock composition, and the rock cycle. Geologists conduct studies to locate rocks that contain important metals that are extracted from mines and locate and produce oil, natural gas, and groundwater. Geologists work to understand Earth processes such as landslides, earthquakes, floods, and volcanic eruptions. Geologists also use historical geology to understand climate change (Schweingruber, Keller, \& Quinn, 2012; Dodick \& Orion, 2003). Given the international need to manage natural hazards, industrial pressures, and sustainability, geology has become an essential topic for primary and secondary school students worldwide. 
Unfortunately, the task of ensuring that geologic content is sufficiently covered is uniquely difficult as compared to similar efforts in other scientific domains. There are few dedicated geology courses in secondary schools; instead, most geology content is embedded within a variety of other courses within the curriculum. Given geology's fragmented distribution across the sciences, it is not surprising that developing a consensus about which of the geology concepts should be taught to schoolchildren is an arduous task. At the same time, clearly identifying the essence and relevance of school-taught geology is changing. Arguments can be made that in a rapidly transforming world, the core geology content has shifted significantly in the past twenty years while our scientific understanding of those core concepts has also substantively changed.

While shifting context provides all nations with a warrant to reconsider the modern core geologic content for primary and secondary schools, nations' educational policies provide additional, varying challenges. Many countries (e.g.: United Kingdom, Japan, Australia) have clearly specified learning targets for geology concepts, national curriculum materials, common textbooks, consistent tests and examinations that define and circumscribe educationally important geology topics, as a matter of policy (McComas \& Olson, 1998). In these settings, existing structures for building consensus may facilitate an update of core geology content while the existence of a national curriculum may discourage stakeholders from taking up the task of updating learning objectives. In other words, if a country has an existing national curriculum, system inertia and competing pressures may actually serve as a barrier to updating required scientific content.

In contrast, the United States, like some other nations, lacks a national consensus on the curriculum in any discipline. Recent U. S. efforts to define national standards such as the Next Generation Science Standards (NGSS) have been attempted, yet no curriculum or standardized guideline for content have been nationally adopted (viz., Slater \& Slater, 2015). The United States Constitution does not provide for federal authority over education, leaving any national collaboration subject to the voluntary participation of the states. At the same time, the economic, political, and environmental implications of the science of geology elicit widely varying responses across the authoritative state agencies. As such the United States' struggle to define core geology content for the primary and secondary classroom settings is likely to mirror similar efforts across international contexts.

This paper describes and documents part of the evolving struggle to establish guidelines for teaching and assessing geology content standards in the United States, as an illustration of the difficulty inherent in coming to a consensus on the essential education students should receive. We provide an overview of the attempts to reform science education and examine which geology concepts have been promoted to serve as a common core of concepts, including those that are currently being promoted by leading science education organizations in the United States.

\section{BACKGROUND AND CONTEXT}

Similar to individual nations, each state of the United States has historically taken on the responsibility of determining which topics are taught and to which aged students. For most of the U.S.'s history, day-to-day decisions about which science topics are taught have been left to individual teachers in individual classrooms (Barrow, 2006; DeBoer, 2000). In the last four decades, decisions about which topics are taught have been more greatly influenced by regulations and policies at the state-level of U.S. government, because that is the governmental level where the licensing and legal certification of U.S. public school teachers occurs (Yaeger, 2000). It has only been in the last decade and a half that the U.S. federal government has become involved in education, and even then it has not federally mandated a unified curriculum for schoolchildren.

Analyzing the history of geology as a stand-alone subject allows one to understand the reasons geology concepts are largely neglected in our primary and secondary school system. Geology doesn't have its own identity as a curriculum focus, forcing it to be embedded within other sciences; most commonly physical or environmental science. Several organizations have attempted to invigorate geology as a core academic subject for school children; these reforms, however, regarding being successfully implemented nationally, have essentially failed. Geology was mostly absent in K-12 education until the late 1960s when the Earth Science Curriculum Project (ESCP) introduced geology as a core subject into education, using an inquiry-driven approach in a frantic response to the launching of the Soviet Sputnik satellite, placing more focus on "logical structure and processes and less emphasis on personal and social applications" (Bybee \& DeBoer, 1994 in Dodick \& Orion, 2003). In the 1970s, the National Association 
of Geology Teachers (NAGT) developed a set of curriculum and instructional materials that focused on plate tectonics, the Crustal Evolution Education Project (CEEP). Although the materials were designed to be adaptable to any curriculum, they failed to convince educators to find value in learning the topic of plate tectonics. By the 1980s there was a shift away from inquiry-oriented teaching nationally, stalling all efforts like ESCP (viz., Dodick \& Orion, 2003).

Within the last 20 years, science education reform efforts have accelerated to meet the need to develop a scientifically literate society that can contribute to a global economy, leading to the generation of documents intended to serve as national curriculum guidelines (Barstow \& Yazijian, 2004; Barstow \& Geary, 2002). It could be argued that leaders in the nation's science education establishment recognized the value of geology concepts by the 1990s, when the American Association for the Advancement of Science (AAAS) produced the Benchmarks for Scientific Literacy (1993) and the National Research Council produced the National Science Education Standards, NSES (1996). However, their suggestions involved embedding the geology concepts in the Earth and Environmental curriculum rather than organizing geology concepts in a distinct discipline-focused curriculum. In an effort to promote a stronger emphasis on geology as a distinct discipline, the National Science Foundation supported production of the Earth Science Literacy Principles, ESLP (2008). In turn the National Research Council decided that having students learn the "big ideas" in science was insufficient to support improving scientific literacy, without also addressing the way that students engage in their learning and understand related to the nature of science. This led to the most recent effort for developing a set of non-binding, national standards recommendations: the Next Generation Science Standards, NGSS (2011). In this most current recommendation for a reform document, the $N G S S$, there still remains little substance of geology as a discipline in its own right. Instead geology again provides supporting concepts or ideas that are embedded across the Earth and Physical Sciences domains. The consistent tendency of the United States science education establishment to provide vacillating guidance as to the core content students should learn in geology reflects a similar lack of coherence across international contexts. Clearly, any single set of standards fails to capture the core beliefs of the majority of geology educators. However, it may be possible that an analysis of the various standards documents, as a group, may have some potential to help address the question: "Which core geology concepts are being advocated for teaching to schoolchildren in the United States?" If so, such efforts may provide a pathway to answer similar questions across international contexts. Data and results from a first such effort, using standards documents from within the United States, is given in the following section.

\section{DATA}

\section{Identifying Standards for Comparison}

For the purposes of this paper, our analysis is confined to those standards that are strictly related to the domain of geology, as written into the four most influential education reform documents in the U.S.: the AAAS' Benchmarks, the NRC's NSES, the NGSS, and the ESLP. The analysis includes topics related to the study of the solid Earth, the materials of which it is made, the structure of those materials, and the processes acting upon them. The major concepts in geology include Earth's systems, plate tectonics, geologic time, Earth's structure, Earth's minerals, fossils, landforms, weathering and erosion, radioactivity, rock composition, and the rock cycle. Standards related to meteorology, climate, environmental science, oceanography, biology, astronomy and the physical sciences were eliminated from the analysis unless the standard in question specifically related to geology. For instance, standards related to the water cycle were included when the standards explicitly referred to the interaction of the cycling water with landforms, but were not included if they appeared to apply strictly to meteorology, or more generally to the movement of water through states of matter.

To facilitate a comparison between the different sets of standards, the content in the standards has been abbreviated into what one might consider concept identifiers. For instance, the AAAS standard which reads:

Sedimentary rock buried deep enough may be re-formed by pressure and heat, perhaps melting and recrystallizing into different kinds of rock. These re-formed rock layers may be forced up again to become land surface and even mountains. Subsequently, this new rock too will erode. Rock bears evidence of minerals, temperatures, and forces that created it. (AAAS, 1993) 
Each bullet is given the concept identifier "rock cycle." An attempt has been made to be as specific about the concept identifiers as possible, honing in on the specific content that is expected to be covered by instruction. In some cases this specificity resulted in labeling two standards that share some content with different concept identifiers. For example, the AAAS provides a standard which reads:

Thousands of layers of sedimentary rock confirm the long history of the changing surface of the earth and the changing life forms whose remains are found in successive layers. The youngest layers are not always found on top, because of folding, breaking, and uplift of layers. (AAAS, 1993)

NSES provides a related standard:

The earth processes we see today, including erosion, movement of lithospheric plates, and changes in atmospheric composition, are similar to those that occurred in the past. Earth history is also influenced by occasional catastrophes, such as the impact of an asteroid or comet. (NRC, 1996)

The first of the two standards clearly indicates instruction in what many in the United States would call "historical geology," the reconstruction of Earth's history using the rock record. The second standard provides for the concept of "uniformitarianism and catastrophism." While "uniformitarianism and catastrophism" are necessary concepts for the instruction of "historical geology," historical geology is not necessary for the instruction of "uniformitarianism and catastrophism." These concepts are not logically equivalent and are therefore given different concept identifiers. However, when a single set of standards breaks a large idea, such as plate tectonics, into several different standards, they are all given the concept identifier. In a closer analysis, it would be useful to dissect the specific content points each set of standards has provided for each concept, but for the purpose of this paper, such an analysis would be unwieldy, and would obscure the analysis of broad differences between standard sets.

The content in the following discussions and the table summarizing the standards is divided into three age brackets: Age Group \#1 (i.e., ages 5-10, or U.S. grades K-5/primary school), Age Group \#2 (i.e., ages 11-13, or U.S. grades 68/middle school), and Age Group \#3 (i.e., ages 14-18, or U.S. grades 9-12/high school). Three tables providing summaries of the standards assigned to each of the Age Groups are found at the end of this section (Tables 1, 2 and $3)$. The ESLP is an exception, and it is not included in this age group bracketing because the ESLP did not assign standards to any particular age or grade level. Instead we offer instead a detailed summary of the ESLP at the end of the paper in Table A-4 in the Appendix.

\section{Describing Standards for Comparison}

The AAAS "Benchmarks for Scientific Literacy”

In 1993, the American Association for the Advancement of Science (AAAS) developed the Benchmarks for Scientific Literacy to determine what all students should know and be able to do in science, mathematics, and technology, given in age groups that end with United States' grades 2, 5, 8, and 12. The Benchmarks are intended to help teachers decide what concepts to include and eliminate from a curriculum, when to teach that curriculum and why. Unlike other attempts at drafting standards, the Benchmarks emphasize technology and history within the science content, although this is not necessarily reflected in the standards related to geology. The geology standards are found within The Physical Setting standards, which additionally contain physical science content, astronomy content, and chemistry content. This content is given in full in Tables A-1, A-2, and A-3 in the Appendix.

In the Benchmarks for Scientific Literacy, students within Age Group \#1 (i.e., ages 5-10) are expected to master the content identified in three standards. These standards are related to describing rock materials, describing minerals and soils, and investigating weathering and erosion (Table 1). Students in the Age Group \#2 (i.e., ages 11-13) are expected to master content contained in fifteen standards, including: the water cycle, the rock cycle, plate tectonics, soils, landforms, and historical geology (Table 2). Students in Age Group \#3 (i.e., ages 14-18) are expected to master five standards, including: the rock cycle, plate tectonics, the age of the Earth, and natural resources (Table 3). 
The National Research Council's "National Science Education Standards"

In 1996, The National Research Council (NRC) published the National Science Education Standards, which are "designed to guide our nation toward a scientifically literate society" (NRC, 1996). One major aspect of the NSES is that they were designed using a notion that teaching and teachers are at the center of science education reform (NRC, 1996). They are standards that focus on what teachers should know and do in the classroom and professional development standards for teachers that focus on "how teachers develop professional knowledge and skill" (NAP, 1996). A defining aspect of NSES is the emphasis placed on process and inquiry within science. Curriculum developers decided it is important for students to understand the processes that occur within science content. The content standards for students are organized by K-4, 5-8, and 9-12 grade levels and encompass inquiry within the various subject areas, science in personal and social perspectives, and the history and nature of science. This content is listed in full in Tables A-1, A-2, and A-3 in the Appendix.

In the National Science Education Standards, students within Age Group \#1 (i.e., ages 5-10) are expected to master the content contained in four standards. Similar to the Age Group \#1 standards in the AAAS' Benchmarks, these standards are related to describing rock materials, minerals and soils, and to investigating weathering and erosion, along with other agents of change on Earth's surface. In addition, the Benchmarks require that students gain some expertise related to the study of fossils (Table 1). Students in the Age Group \#2 (i.e., ages 11-13) are expected to master content contained in ten standards. Similar to the AAAS' Benchmarks, this content includes: the water cycle, rock cycle, plate tectonics, soils, and landforms. The NSES also includes a standard related to uniformitarianism and catastrophism, which could be likened to the AAAS' standards listing historical geology. The NSES further adds standards related to the role of water in weathering and erosion, biogeology, and fossils (Table 2). Students in Age Group \#3 (i.e., ages 14-18) are expected to master six standards. Like the Benchmarks, the NSES includes a core standard related to plate tectonics. In addition, the Age Group \#3 NSES standards include the concepts of Earth's interior, energy cycles and biochemical cycles, geological time and radiometric dating, and temporal scales (Table $3)$.

\section{The Next Generation Science Standards}

The National Research Council (NRC), the National Science Teachers Association (NSTA), the American Association for the Advancement of Science (AAAS), and NGSS coordinating entity, Achieve, Inc., describe a twostep process to develop the Next Generation Science Standards. Step one involved the NRC convening a panel of experts and subsequently creating the Framework for K-12 Science Education (Schweingruber, Keller, \& Quinn, 2012) document. The main objectives of NGSS are described in The National Research Council's (NRC) Framework (2012). "A vision of what it means to be proficient in science" stems from viewing "science as both a body of knowledge and an evidence-based, model and theory building enterprise that continually extends, refines, and revises knowledge" (NGSS, 2013a).

For the second step, Achieve, Inc. was contracted to create a conversion of the NRC Framework into standards for schools called the Next Generation Science Standards, NGSS. The NGSS are organized into three dimensions: 1) Practices describe the behaviors of scientists as they engage in investigation, build models, and construct theories about the natural world; 2) Cross-cutting concepts are a way of linking different domains of science; and 3) Disciplinary core ideas are intended to focus K-12 science curriculum, instruction, and assessments on the most important aspects of science. The NGSS attempted to incorporate systems, processes, and technology within the content. However, after evaluating the NGSS, it is clear Achieve, Inc. was not fully able to complete the task it initially set out to accomplish.

The Next Generation Science Standards were developed for a multitude of reasons to capitalize on our nation's most prized economic resource- $-\mathrm{K}-12$ students. NGSS documents state that U.S. students need to leave secondary school being college- and career- ready, to successfully compete in a global society, and to know how to adapt to our everchanging, unpredictable world (NGSS, 2013). Rationales like the few stated above may seem obvious. But such pronouncements leave the actual pathways to success open to individuals to decide: How do school districts know they are developing our most prized resource to its maximum capacity? When evaluating the current U.S. K-12 public school system's effectiveness in science education, Achieve, Inc., documents proclaim that it is apparent that 
"science education is performing far below par" (NGSS, 2013a). Such a perspective is presented to motivate the recent development of NGSS: 1) Reduction of the United States' competitive economic edge; 2) Lagging achievement of U.S. students; 3) Essential preparation for all careers in the modern workforce; and 4) Scientific and technological literacy for an educated society (NGSS, 2013a). The framework for teaching geology concepts to schoolchildren in the NGSS are organized by Disciplinary Core Ideas (DCI). The full content of the NGSS related to geology is given in Tables A-1, A-2, and A-3 in the Appendix.

In the NGSS, students within Age Group \#1 (i.e., ages 5-10) are expected to master the content contained in seventeen standards. The only shared overlap between the Age Group \#1 standards prescribed in the Benchmarks or the NSES, and the NGSS is related to weathering and erosion. Instead, the NGSS recommends that students master a number of other concepts, including concepts related to natural hazards, water reservoirs, natural resources, and historical geology (Table 1). Students in the Age Group \#2 (i.e., ages 11-13) are expected to master content contained in ten standards. Like the AAAS' Benchmarks and NRC's NSES, this content includes: the water cycle, plate tectonics, and historical geology. Standards related to biogeochemical cycles and the role of water in weathering and erosion mirror Age Group \#2 content from the NSES, and the NGSS adds additional standards related to temporal scales, natural resources, and natural hazards (Table 2). Students in Age Group \#3 (i.e., ages 1418) are expected to master fourteen standards. Like the Benchmarks and the NSES, the NGSS includes a standard related to plate tectonics. Additional topics added to the curriculum in the NGSS are actually too numerous to list in the space available here, so they are summarized in Table 3.

\section{Earth Science Literacy Principles (ESLP)}

The development of the curriculum guidelines known as the Earth Science Literacy Principles (ESLP) was created in a series of workshops initially funded by the National Science Foundation to "define a set of essential ideas that a literate American should know about the geosciences" (viz., URL: http://earthscienceliteracy.org). The ESLP are the only widely known education standards project specifically attempting to include the traditional domain of geology, along with its overarching emphasis on the science of Earth's systems. The framers of ESLP wanted to develop a geology curriculum that contained the most important geology concepts - the "big ideas" - and it was their hope that these "big ideas" would also be rapidly incorporated into school textbooks and curriculum materials. The ESLP reform aggressively advocates that an Earth-science-literate person: (i) understands the fundamental concepts of Earth's many systems; (ii) knows how to find and assess scientifically credible information about Earth; (iii) communicates about Earth science in a meaningful way; and (iv) is able to make informed and responsible decisions regarding Earth and its resources. Recommendations of the ESLP are listed in full in Table A-4 of the Appendix, and by inspection one can see that traditional geology concepts loom large across this education reform document.

$E L S P$ has not been widely adopted by schools across the U.S. One reason is that its developers were not nearly as tightly connected to national education policy makers, movers, and shakers as other efforts described above. Its development efforts were funded by the National Science Foundation in 2008 as collaborative awards to Washington University (who went on to play a large leadership role in the NGSS a few years later); the IRIS Incorporated Research Institutions for Seismology (a global Earth science data distribution center); and the nonprofit DC-beltway located College of Exploration (an entity that doesn't actually teach college courses but instead receives funds to develop K-12 curricula, provides professional development workshops for teachers, and coordinates conferences) with a limited website currently hosted by UCAR University Consortium for Atmospheric Research. Whether or not the suggested curriculum guidelines are of high quality, other than announcing its suggestions to the world, there has been little distribution through either the traditional academic literature or successful influence with policy makers.

Another reason that ESLP has had very limited adoption is that the advocated standards are divided into nine big ideas, but without indication or guidance about what to actually teach at specified age or grade levels. If a state were to implement the ESLP recommendations, it would be unclear when to teach each big idea. Another similar problem is that the ESLP document's emphasis is often placed on scientific content other than geology. The ESLP was written to "define a set of essential ideas that a literate American should know about the geosciences" (viz., URL: http://earthscienceliteracy.org) however, the core geology concepts are lost within larger and louder environmental science and biology content also listed. 
Table 1. Age Group 1 content standards from the AAAS, NRC and Achieve, Inc. documents.

\begin{tabular}{|c|c|c|c|}
\hline & AAAS Benchmarks & NRC NSES & Achieve, Inc., NGSS \\
\hline Age Group \#1 & 5-10 (Grades K-5) & 5-9 (Grades K-4) & 5-10 (Grades K-5) \\
\hline Raw Number of Standards & 3 & 4 & 17 \\
\hline Topics Covered & $\begin{array}{l}\text { - Describing rock materials } \\
\text { - Minerals and soils } \\
\text { - Weathering and erosion }\end{array}$ & $\begin{array}{l}\text { - Describing rock materials } \\
\text { - Resources and soils } \\
\text { - Fossils } \\
\text { - Earth changing processes }\end{array}$ & $\begin{array}{l}\text { - Biogeology } \\
\text { - Human impacts (2) } \\
\text { - Natural resources (2) } \\
\text { - Fossils } \\
\text { - Historical geology } \\
\text { - Plate tectonics } \\
\text { - Earth systems } \\
\text { - Water reservoirs (2) } \\
\text { - Temporal scales } \\
\text { - Natural hazards (2) } \\
\text { - Weathering and erosion } \\
\text { - }(2) \\
\text { - Maps }\end{array}$ \\
\hline
\end{tabular}

Table 2. Age Group 2 content standards from the AAAS, NRC and Achieve, Inc. documents

\begin{tabular}{|c|c|c|c|}
\hline & AAAS Benchmarks & NRC NSES & Achieve, Inc. NGSS \\
\hline Age Group \#2 & 11-13 (Grades 6-8) & $10-13$ (Grades 5-8) & 11-13 (Grades 6-8) \\
\hline Raw Number of Standards & 15 & 10 & 9 \\
\hline Topics Covered & $\begin{array}{l}\text { - Plate tectonics (4) } \\
\text { - Water cycle } \\
\text { - Rock cycle } \\
\text { - Soils } \\
\text { - Landforms } \\
\text { - Earth structure } \\
\text { - Sedimentary rock } \\
\text { formation } \\
\text { - Historical geology } \\
\text { - Earth formation } \\
\text { - Weathering and erosion } \\
\text { - Volcanoes and } \\
\text { - Earthquakes } \\
\text { - Earth change processes }\end{array}$ & $\begin{array}{l}\text { - Plate tectonics } \\
\text { - Water cycle } \\
\text { - Rock cycle } \\
\text { - Soils } \\
\text { - Landforms } \\
\text { - Earth structure } \\
\text { - Water in weathering and } \\
\text { erosion } \\
\text { - Biogeology } \\
\text { - Uniformitarianism and } \\
\text { - catastrophism } \\
\text { - Fossils }\end{array}$ & $\begin{array}{l}\text { - Plate tectonics (2) } \\
\text { - Water cycle } \\
\text { - Historical geology/fossils } \\
\text { - Energy } \\
\text { cycles/biogeochemical } \\
\text { cycles } \\
\text { - Temporal and spatial } \\
\text { scales } \\
\text { - Water in weathering and } \\
\text { erosion } \\
\text { - Natural resources } \\
\text { - Natural hazards }\end{array}$ \\
\hline
\end{tabular}

Table 3. Age Group 3 content standards from the AAAS, NRC and Achieve, Inc. documents

\begin{tabular}{|c|c|c|c|}
\hline & AAAS Benchmarks & NRC NSES & Achieve, Inc., NGSS \\
\hline Age Group \#3 & 14-18 (Grades 9-12) & 14-18 (Grades 9-12) & 14-18 (Grades 9-12) \\
\hline Raw Number of Standards & 5 & 6 & 14 \\
\hline Topics Covered & $\begin{array}{l}\text { - Plate tectonics } \\
\text { - Rock cycle } \\
\text { - Earth age } \\
\text { - Natural resources }\end{array}$ & $\begin{array}{l}\text { - Plate tectonics } \\
\text { - Earth's interior } \\
\text { - Biogeochemical cycles } \\
\text { - Energy cycles/ } \\
\text { biochemical cycles } \\
\text { - Geological } \\
\text { time/radiometric dating } \\
\text { - Temporal scales }\end{array}$ & $\begin{array}{l}\text { - Plate tectonics (4) } \\
\text { - Extraterrestrial materials } \\
\text { - Radiometric dating } \\
\text { - Feedback effects } \\
\text { - Earth structure/ } \\
\text { convection cells (2) } \\
\text { - Geologic time/time scales } \\
\text { - Plate tectonics/geologic } \\
\text { - history } \\
\text { - Water as a geologic agent } \\
\text { - Biogeology } \\
\text { - Seismic waves and earth } \\
\text { structure } \\
\end{array}$ \\
\hline
\end{tabular}




\section{ANALYSIS}

In order to make a more meaningful comparison of the work produced by each of these groups, the three sets of standards are compared for the number of standards suggested by each group, and the extent to which the groups' standards overlapped with each other. The analysis of the content overlap is constrained to the standards in Age Groups 1 and 2, as over 75\% of Age Group 3 students in the United States do not enroll in courses in which geology content is presented.

The AAAS and NRC documents suggest 23 and 20 standards, respectively, across all three age groups. When constrained to Age Groups 1 and 2, the documents suggest instruction related to 18 and 14 standards, respectively. The Achieve, Inc. documents suggest instruction related to 40 standards across all three age groups, which is reduced to 26 suggested standards when the analysis is constrained to Age Groups 1 and 2 (Table 4).

Table 4. Comparison of the raw number of content standards in the AAAS, NRC and Achieve, Inc. documents

\begin{tabular}{l|c|c|c}
\hline & AAAS Benchmarks & NRC NSES & Achieve, Inc. NGSS \\
\hline $\begin{array}{l}\text { Raw Number of Standards } \\
\text { Across Age Groups 1, 2, and 3 }\end{array}$ & 23 & 20 & 40 \\
\hline $\begin{array}{l}\text { Raw Number of Standards } \\
\text { Across Age Groups 1 and 2 }\end{array}$ & 18 & 14 & 26 \\
\hline
\end{tabular}

Standards for the three documents were compared for overlap in content across Age Groups 1 and 2. This analysis indicates that all three documents agree upon instruction related to plate tectonics and the water cycle. All other geological concepts were either agreed upon by just two groups, or were suggested by one group. This analysis is illustrated in Table 5. Numbers in parentheses indicate the number of times a concept was identified as a separate standard.

Table 5. Comparison of the concepts suggested for Age Groups 1 and 2.

\begin{tabular}{|c|c|c|c|}
\hline & AAAS Benchmarks & NRC NSES & Achieve, Inc., NGSS \\
\hline Raw Number of Standards & 18 & 14 & 26 \\
\hline $\begin{array}{l}\text { Topics Covered by AAAS, } \\
\text { NRC and Achieve, Inc. }\end{array}$ & $\begin{array}{l}\text { - Plate tectonics (4) } \\
\text { - Water cycle }\end{array}$ & $\begin{array}{l}\text { - Plate tectonics (2) } \\
\text { - Water cycle }\end{array}$ & $\begin{array}{l}\text { - Plate tectonics (3) } \\
\text { - Water cycle }\end{array}$ \\
\hline $\begin{array}{l}\text { Topics Covered by AAAS } \\
\text { and NSES }\end{array}$ & $\begin{array}{l}\text { - Rock cycle } \\
\text { - Describing rock materials } \\
\text { - Landforms } \\
\text { - Soils } \\
\text { - Earth structure } \\
\text { - Earth changing processes }\end{array}$ & $\begin{array}{l}\text { - Rock cycle } \\
\text { - Describing rock materials } \\
\text { - Landforms } \\
\text { - Soils } \\
\text { - Earth structure } \\
\text { - Earth changing processes }\end{array}$ & \\
\hline $\begin{array}{l}\text { Topics Covered by NSES } \\
\text { and Achieve, Inc. }\end{array}$ & & $\begin{array}{l}\text { - Biogeology } \\
\text { - Fossils } \\
\text { - Water's role in weathering } \\
\text { and erosion }\end{array}$ & $\begin{array}{l}\text { - Biogeology } \\
\text { - Fossils } \\
\text { - Water's role in } \\
\text { weathering and erosion }\end{array}$ \\
\hline \multirow[t]{2}{*}{$\begin{array}{l}\text { Topics Covered by AAAS } \\
\text { and Achieve, Inc. }\end{array}$} & $\begin{array}{l}\text { - Weathering and erosion } \\
\text { - Historical geology }\end{array}$ & & $\begin{array}{l}\text { - Weathering and erosion (2) } \\
\text { - Historical geology }\end{array}$ \\
\hline & AAAS Benchmarks & NRC NSES & Achieve, Inc., NGSS \\
\hline Irreconcilable Standards & $\begin{array}{l}\text { - Minerals and soils } \\
\text { - Sedimentary rock formation } \\
\text { - Earth formation } \\
\text { - Earth described } \\
\text { - Volcanoes and earthquakes }\end{array}$ & $\begin{array}{l}\text { - Resources and soils } \\
\text { - Uniformitarianism and } \\
\text { catastrophism }\end{array}$ & $\begin{array}{l}\text { - Maps } \\
\text { - Human impacts (2) } \\
\text { - Earth systems } \\
\text { - Water reservoirs (2) } \\
\text { - Natural hazards (3) } \\
\text { - Historical geology/fossils } \\
\text { - Temporal and spatial } \\
\text { - } \text { scales } \\
\text { - Enemporal scales } \\
\text { - Nycles } \\
\text { - Natural Resources (3) }\end{array}$ \\
\hline
\end{tabular}


In an effort to quantify the agreement between standards, the percentage of overlap was calculated by dividing the total standards agreed upon by groups by the total number of standards suggested by the groups. For instance, all three documents agreed upon the inclusion of plate tectonics and the water cycle. The groups suggested an aggregate of 12 standards related to these topics, while they suggested a total of 58 standards overall in Age Groups 1 and 2 . This represents an agreement of $21 \%$ between the three groups. Percent agreement across the four possible combinations of standards is provided in Table 6.

Table 6. Percentage agreement between the AAAS, NRC and Achieve, Inc. documents, Age Groups 1 and 2

\begin{tabular}{|c|c|c|c|c|}
\hline & AAAS/NRC/Achieve, Inc. & AAAS/NRC & AAAS/Achieve, Inc. & NRC/Achieve, Inc. \\
\hline Percent Agreement & $21 \%$ & $63 \%$ & $32 \%$ & $33 \%$ \\
\hline
\end{tabular}

It is possible that standards from each document could be dissected and rearranged to develop standards that show a higher degree of agreement. On the other hand, standards could also be edited to reduce repetition, resulting in a lower percentage of agreement. For instance, in the NGSS, one of the standards related to plate tectonics appears, verbatim, in another standard. If this single standard was removed in an editing process, the NGSS's agreement with all calculations would be reduced by approximately $2 \%$. In order to avoid manipulation of the analysis in either direction, the standards are analyzed as written.

Given the number of times content is repeatedly seen in standards, a comparison was conducted on two topics in order to provide some indication of what these repetitions accomplish in the curriculum. The full content standards related to plate tectonics, which is seen repeatedly in each of the three documents are given in Table 7 . The full content standards related to natural resources and natural hazards, which are only repeated in the NGSS are given in Tables 8 and 9, in order to provide additional insights into the nature of repetitions in the scientific content. 
Table 7. Comparison of repetitions in standards related to plate tectonics

\begin{tabular}{|c|c|c|c|}
\hline & AAAS & NSES & NGSS \\
\hline Age Group 1 & & & $\begin{array}{l}\text { The locations of mountain } \\
\text { ranges, deep ocean trenches, } \\
\text { ocean floor structures, } \\
\text { earthquakes, and volcanoes occur } \\
\text { in patterns. Most earthquakes } \\
\text { and volcanoes occur in bands } \\
\text { that are often along the } \\
\text { boundaries between continents } \\
\text { and oceans. Major mountain } \\
\text { chains form inside continents or } \\
\text { near their edges. Maps can help } \\
\text { locate the different land and } \\
\text { water features areas of Earth }\end{array}$ \\
\hline \multirow{5}{*}{ Age Group 2} & $\begin{array}{l}\text { Matching coastlines and } \\
\text { similarities in rock types and life } \\
\text { forms suggest that today's } \\
\text { continents are separated parts of }\end{array}$ & \multirow{5}{*}{$\begin{array}{l}\text { Lithospheric plates on the scales } \\
\text { of continents and oceans } \\
\text { constantly move at rates of } \\
\text { centimeters per year in response } \\
\text { to movements in the mantle. } \\
\text { Major geological events, such as } \\
\text { earthquakes, volcanic eruptions, } \\
\text { and mountain building, result } \\
\text { from these plate motions }\end{array}$} & \multirow{5}{*}{$\begin{array}{l}\text { Tectonic processes continually } \\
\text { generate new ocean sea floor at } \\
\text { ridges and destroy old sea floor } \\
\text { at trenches } \\
\text { Maps of ancient land and water } \\
\text { patterns, based on investigations } \\
\text { of rocks and fossils, make clear } \\
\text { how Earth's plates have moved } \\
\text { great distances, collided, and } \\
\text { spread apart }\end{array}$} \\
\hline & $\begin{array}{l}\text { what was long ago a single } \\
\text { continent }\end{array}$ & & \\
\hline & $\begin{array}{l}\text { The outer layer of the earth- } \\
\text { including both the continents and } \\
\text { the ocean basins-consists of } \\
\text { separate plates }\end{array}$ & & \\
\hline & $\begin{array}{l}\text { The earth's plates sit on a dense, } \\
\text { hot, somewhat melted layer of } \\
\text { the earth. The plates move very } \\
\text { slowly, pressing against one } \\
\text { another in some places and } \\
\text { pulling apart in other places, } \\
\text { sometimes scraping alongside } \\
\text { each other as they do. Mountains } \\
\text { form as two continental plates, or } \\
\text { an ocean plate and a continental } \\
\text { plate, press together }\end{array}$ & & \\
\hline & $\begin{array}{l}\text { There are worldwide patterns to } \\
\text { major geological events (such as } \\
\text { earthquakes, volcanic eruptions, } \\
\text { and mountain building) that } \\
\text { coincide with plate boundaries }\end{array}$ & & \\
\hline
\end{tabular}

Table 8. NGSS Standards related to natural hazards

\begin{tabular}{|c|c|}
\hline & NGSS \\
\hline \multirow{2}{*}{ Age Group 1} & $\begin{array}{l}\text { A variety of natural hazards result from natural processes. Human cannot eliminate natural hazards but } \\
\text { can take steps to reduce their impacts }\end{array}$ \\
\hline & $\begin{array}{l}\text { A variety of hazards result from natural processes (e.g., earthquakes, tsunamis, volcanic eruptions). } \\
\text { Humans cannot eliminate the hazards but can take steps to reduce their impacts }\end{array}$ \\
\hline Age Group 2 & $\begin{array}{l}\text { Mapping the history of natural hazards in a region, combined with an understanding of related geologic } \\
\text { forces can help forecast the locations and likelihoods of future events }\end{array}$ \\
\hline
\end{tabular}


Table 9. NGSS Standards related to natural resources

\begin{tabular}{l|l}
\hline Age Group 1 & $\begin{array}{l}\text { NGSS } \\
\text { Living things need water, air, resources from the land, and they live in places that have the things they } \\
\text { need. Humans use natural resources for everything they do }\end{array}$ \\
\hline $\begin{array}{l}\text { Energy and fuels that humans use are derived from natural sources, and their use affects the environment } \\
\text { in multiple ways. Some resources are renewable over time, and others are not }\end{array}$ \\
\hline Age Group 2 & $\begin{array}{l}\text { Humans depend on Earth's land, ocean, atmosphere, and biosphere for many different resources. } \\
\text { Minerals, fresh water, and biosphere resources are limited, and many are not renewable or replaceable } \\
\text { over human lifetimes. These resources are distributed unevenly around the planet as a result of past } \\
\text { geologic processes }\end{array}$ \\
\hline
\end{tabular}

\section{RESULTS \& CONCLUSIONS}

There are several notable differences between the sets of standards that have been written in the attempt to guide geology education in the United States. The most important of these differences is related to the scope of the science suggested by these documents.

As written, the NGSS suggests twice as many content standards as the AAAS and NRC documents. In reviewing the standards presented in Tables 8 and 9, it is possible that a number of standards presented by the NGSS are redundant and could be eliminated from the curriculum. For instance, the two NGSS standards for natural hazards in Age Group 1 are virtually identical, while the NGSS standards for natural resources in Age Group 2 are merely a restatement of the standards in Age Group 1. The same content is presented in elevated vocabulary, but there is no substantive difference. This is a case in which a greater number of standards do not provide additional insight into what good instruction might look like. This is in contrast to the treatment of plate tectonics presented in Table 7. In that case, we can see that more standards can provide additional instructional information. The AAAS treatment of the topic includes more standards than the NRC or Achieve, Inc.'s presentation, and those standards are used to specify the scope and depth of the content to be taught. Clearly sometimes more is more and sometimes more is less. Having said that, even if the standards were edited to eliminate redundancy, the NGSS would still contain far more standards than the other two documents. Quite simply, the NGSS requires that more content must be covered through instruction.

Then there is the matter of what content should be covered. If one were to ask the reasonable person on the street what geologists study, a commonly expected response might be that geology is the study of rocks. It is therefore surprising that the most recent effort to define the core geology content does not include content that would educate students about the nature of rocks. It also does not include content related to the rock cycle. As a team of educators who have been engaged in geology education for well over half a century, we find this to be quite bizarre. One wonders how students are to discuss historical geology, plate tectonics or minerals and ores, without first understanding what rocks are and how they are made. The NGSS fails to include other geology content that, while not as crucial as the concept of the rock, would be considered foundational to higher order discussions of human interactions with the planet Earth, including soils, landforms, and the nature of ores and mineral deposits. While the NGSS may aspire to provide instruction on socially relevant topics, it has undercut the foundational education required to engage in those topics intelligently. Similarly, the NRC document does not contain explicit content related to generalized weathering and erosion, or to historical geology. While an argument could be made that these topics are included in the documents implicitly, we would argue that the purpose of a standards document is to make instructional objectives explicit. Implicit guidance in the turbulent waters of the educational landscape is no guidance at all.

Additional differences between these standards documents include matters related to the sequencing of the science, scientific accuracy and the language used to present the suggested scientific content. However, it seems logical that agreement needs to be made about the core scientific content before such matters are contemplated, and the United States science education community has a long way to go before reaching that point. This is particularly discouraging when one considers that the United States has invested tens of millions of dollars and tens of thousands of man-hours, in just the most recent effort. 
As matters stand, primary and secondary school administrators, curriculum writers and instructors in local contexts, are left to sort through a mass of conflicting information using whatever resources might be available to them. Despite the burden of that task, that work must be accomplished, as there are few educational tenets that hold more certainty than this one idea: quality education is inextricably linked to instruction that is driven by clear educational objectives (Hunter 1972). As boldly stated by Tamir and Jungwirth (1972): "It is now generally conceded that a definition of teaching objectives has to precede curriculum construction as well as curriculum evaluation, and must serve as a guiding principle for any teaching process." Therefore, we propose that the burden of clearly defining core education standards cannot be left to those educational settings that possess the resources to manage such work. Such a choice increases national and international inequities in education.

In the interest of ensuring equitable educational opportunities for all students, in all settings, we urge the geology and science education communities to band together to construct a set of geology education standards that do not define all that we wish students might learn about geology. Rather, we recommend a set of standards that define the minimum geological content that every child should be given an opportunity to learn. We further recommend that such standards should be written in the clearest, most common verbiage, in language accessible to the everyday classroom instructor. Finally, in the interest of maximizing the use of limited resources, we recommend that educational agencies and stakeholders do away with the strategy of beginning every standards writing adventure from a blank slate. Instead, we believe that it is the wisest course of action to build upon what has come before, seeking consensus among existing documents across national and international contexts, effectively updating content for a modern age while leveraging the wisdom of those who have come before us.

\section{AUTHOR BIOGRAPHIES}

Sarah Katie Guffey is a Ph.D. student at the University of Wyoming where she is working on developing conceptual diagnostic surveys for geology educators. Correspondence about this project should be directed directly to her. Email: katie@caperteam.com

Stephanie Slater is the Director of the CAPER Center for Astronomy \& Physics Education Research and a scholar in discipline-based education research across the Earth and space sciences. Email: stephanie@caperteam.com

Sharon Schleigh is an Assistant Professor of Science Education at East Carolina University where she is the Assistant Director of the East Carolina Space Grant Collaborative. Email: schleighs14@ecu.edu

Tim Slater holds the University of Wyoming Excellence in Higher Education Endowed Chair of Science Education where he is appointed to the rank of Professor. Email: tslater@uwyo.edu

Inge Heyer is a Visiting Assistant Professor of Physics at Loyola University Maryland, where she teaches physics, astronomy, and integrated science for elementary education majors. Email: iheyer@loyola.edu

\section{REFERENCES}

American Association for the Advancement of Science. (1993). Benchmarks for science literacy. Oxford University Press, USA.

Barrow, L. H. (2006). A brief history of inquiry: From Dewey to standards. Journal of Science Teacher Education, 17(3), 265278.

Barstow, D., Geary, E., \& Yazijian, H. (2002). The Revolution in Earth and Space Science Education. Hands On!, 25(1), 8-11.

Barstow, D., \& Yazijian, H. Z. (2004). Placing urban schools at the forefront of the revolution in Earth science education. Journal of Geoscience Education, 52(5), 416.

DeBoer, G. E. (2000). Scientific literacy: Another look at its historical and contemporary meanings and its relationship to science education reform. Journal of research in science teaching, 37(6), 582-601.

Dodick, J., \& Orion, N. (2003). Geology as an historical science: Its perception within science and the education system. Science \& Education, 12(2), 197-211.

Earth Science Literacy Initiative. (2010). Earth science literacy principles: The big ideas and supporting concepts of Earth science. Arlington, VA: National Science Foundation. Retrieved from: http://www.earthscienceliteracy.org/es_literacy_6may10_.pdf

Gonzales, L., \& Keane, C. (2011). Status of the geoscience workforce 2011. American Geological Institute, Alexandria. 
Retrieved from http://www.americangeosciences.org/sites/default/files/StatusoftheWorkforce2011 loverview.pdf

Hunter, M. (1972). Appraising the instructional process. Retrieved from ERIC at http://files.eric.ed.gov/fulltext/ED139792.pdf McComas, W. F., \& Olson, J. K. (1998). The nature of science in international science education standards documents. In The nature of science in science education (pp. 41-52). Springer Netherlands.

NGSS (2013a). Next Generation Science Standards Executive Summary, Achieve, Inc. retrieved from http://www.nextgenscience.org/resources/ngss-introduction-and-overview

NGSS (2013b). Next Generation Science Standards Framework, Achieve, Inc. retrieved from $\mathrm{http}: / / w w w . n e x t g e n s c i e n c e . o r g / f r a m e w o r k-k-12-s c i e n c e-e d u c a t i o n$

NGSS Lead States. (2013). Next Generation Science Standards: For States, By States. Washington, DC: The National Academies Press.

National Research Council (Ed.). (1996). National science education standards. National Academy Press.

Schweingruber, H., Keller, T., \& Quinn, H. (Eds.). 2012. A Framework for K-12 Science Education: Practices, Crosscutting Concepts, and Core Ideas. National Academies Press.

Slater, S. J., \& Slater, T. F. (2015). Questioning the fidelity of the next generation science standards for astronomy and space sciences education. Journal of Astronomy \& Earth Sciences Education, 2(1), 51-64.

Tamir, P., \& Jungwirth, E. (1972). Teaching objectives in biology: Priorities and expectations. Science Education, 56(1), $31-39$.

Yaeger, E. A. (2000). Thoughts on wise practice in the teaching of social studies. Social Education, 64(6), 352-352. 


\section{APPENDIX}

Table A-1. AAAS, NSES, NGSS Ages 5-10 (Grades K-5)

AAAS 1. Chunks of rocks come in many sizes and shapes, from boulders to grains of sand and even smaller

2. Chunks of rocks come in many sizes and shapes, from boulders to grains of sand and even smaller

3. Waves, wind, water, and ice shape and reshape the earth's land surface by eroding rock and soil in some areas and depositing them in other areas, sometimes in seasonal layers

4. Rock is composed of different combinations of minerals. Smaller rocks come from the breakage and weathering of bedrock and larger rocks. Soil is made partly from weathered rock, partly from plant remains-and also contains many living organisms

NSES 1. Earth materials are solid rocks and soils, water, and the gases of the atmosphere. The varied materials have different physical and chemical properties, which make them useful in different ways, for example, as building materials, as sources of fuel, or for growing the plants we use as food. Earth materials provide many of the resources that humans use

2. Soils have properties of color and texture, capacity to retain water, and ability to support the growth of many kinds of plants, including those in our food supply

3. Fossils provide evidence about the plans and animals that lived long ago and the nature of the environment at that time

4. The surface of the earth changes. Some changes are due to slow processes, such as erosion and weathering, and some changes are due to rapid processes, such as landslides, volcanic eruptions, and earthquakes

NGSS 1. Living things need water, air, resources from the land, and they live in places that have the things they need. Humans use natural resources for everything they do

2. Plants and animals can change their environment

3. Things that people do to live comfortably can affect the world around them. But they can make choices that reduce their impacts on the land, water, air, and other living things

4. A variety of natural hazards result from natural processes. Human cannot eliminate natural hazards but can take steps to reduce their impacts

5. Wind and water can change the shape of the land

6. Maps show where things are located. One can map the shapes and kinds of land and water in any area

7. Some events happen very quickly; others occur very slowly, over a time period much longer than one can observe

8. Water is found in the ocean, rivers, lakes, and ponds. Water exists as solid ice and in liquid form

9. Local, regional, and global patterns of rock formations reveal changes over time due to earth forces, such as earthquakes. The presence and location of certain fossil types indicate the order in which rock layers were formed

10. Rainfall helps to shape the land and affects the types of living things found in a region. Water, ice, wind, living organisms, and gravity break rocks, soils, and sediments into smaller particles and move them around

11. The locations of mountain ranges, deep ocean trenches, ocean floor structures, earthquakes, and volcanoes occur in patterns. Most earthquakes and volcanoes occur in bands that are often along the boundaries between continents and oceans. Major mountain chains form inside continents or near their edges. Maps can help locate the different land and water features areas of Earth

12. Living things affect the physical characteristics of their regions

13. Energy and fuels that humans use are derived from natural sources, and their use affects the environment in multiple ways. Some resources are renewable over time, and others are not

14. A variety of hazards result from natural processes (e.g., earthquakes, tsunamis, volcanic eruptions). Humans cannot eliminate the hazards but can take steps to reduce their impacts

15. Earth's major systems are the geosphere (solid and molten rock, soil, and sediments), the hydrosphere (water and ice), the atmosphere (air), and the biosphere (living things, including humans). These systems interact in multiple ways to affect Earth's surface materials and processes. The ocean supports a variety of ecosystems and organisms, shapes landforms, and influences climate. Winds and clouds in the atmosphere interact with the landforms to determine patterns of weather

16. Nearly all of Earth's available water is in the ocean. Most fresh water is in glaciers or underground; only a tiny fraction is in streams, lakes, wetlands, and the atmosphere

17. Human activities in agriculture, industry, and everyday life have had major effects on the land, vegetation, streams, ocean, air, and even outer space. But individuals and communities are doing things to help protect Earth's resources and environments 
Table A-2. AAAS, NSES, NGSS Ages 11-13 (Grades 6-8).

\begin{tabular}{l|ll} 
AAAS & 1. The earth is mostly rock. Three-fourths of the earth's surface is covered by a relatively thin layer of water (some of
\end{tabular} it frozen), and the entire planet is surrounded by a relatively thin layer of air

2. Water evaporates from the surface of the earth, rises and cools, condenses into rain or snow, and falls again to the surface. The water falling on land collects in rivers and lakes, soil, and porous layers of rock, and much of it flows back into the oceans. The cycling of water in and out of the atmosphere is a significant aspect of the weather patterns on Earth

3. The interior of the earth is hot. Heat flow and movement of material within the earth cause earthquakes and volcanic eruptions and create mountains and ocean basin. Gas and dust from large volcanoes can change the atmosphere

4. Some changes in the earth's surface are abrupt (such as earthquakes and volcanic eruptions) while other changes happen very slowly (such as uplift and wearing down of mountains)

5. The earth's surface is shaped in part by the motion of water (including ice) and wind over very long times, which acts to level mountain ranges. Rivers and glacial ice carry off soil and break down rock, eventually depositing the material in sediments or carrying it in solution to the sea

6. Sediments of sand and smaller particles (sometimes containing the remains of organisms) are gradually buried and are cemented together by dissolved minerals to form solid rock again

7. Sedimentary rock buried deep enough may be re-formed by pressure and heat, perhaps melting and recrystallizing into different kinds of rock. These re-formed rock layers may be forced up again to become land surface and even mountains. Subsequently, this new rock too will erode. Rock bears evidence of minerals, temperatures, and forces that created it

8. Thousands of layers of sedimentary rock confirm the long history of the changing surface of the earth and the changing life forms whose remains are found in successive layers. The youngest layers are not always found on top, because of folding, breaking, and uplift of layers

9. Although weathered rock is the basic component of soil, the composition and texture of soil and its fertility and resistance to erosion are greatly influenced by plant roots and debris, bacteria, fungi, worms, insects, rodents, and other organisms

10. There are a variety of different land forms on the earth's surface (such as coastlines, rivers, mountains, deltas, and canyons)

11. Matching coastlines and similarities in rock types and life forms suggest that today's continents are separated parts of what was long ago a single continent

12. The earth first formed in a molten state and then the surface cooled into solid rock

13. The outer layer of the earth - including both the continents and the ocean basins - consists of separate plates

14. The earth's plates sit on a dense, hot, somewhat melted layer of the earth. The plates move very slowly, pressing against one another in some places and pulling apart in other places, sometimes scraping alongside each other as they do. Mountains form as two continental plates, or an ocean plate and a continental plate, press together

15. There are worldwide patterns to major geological events (such as earthquakes, volcanic eruptions, and mountain building) that coincide with plate boundaries

\begin{tabular}{l|l} 
NSES & 1 . The solid earth is layered with a lithosphere; hot, convecting mantle; and dense, metallic core
\end{tabular}

2. Lithospheric plates on the scales of continents and oceans constantly move at rates of centimeters per year in response to movements in the mantle. Major geological events, such as earthquakes, volcanic eruptions, and mountain building, result from these plate motions

3. Landforms are the result of a combination of constructive and destructive forces. Constructive forces include crustal deformation, volcanic eruption, and deposition of sediment, while destructive forces include weathering and erosion

4. Some changes in the solid earth can be described as the "rock cycle." Old rocks at the earth's surface weather, forming sediments that are buried, then compacted, heated, and often recrystallized into new rock. Eventually, those new rocks may be brought to the surface by the forces that drive plate motions, and the rock cycle continues

5. Soil consists of weathered rocks and decomposed organic material from dead plants, animals, and bacteria. Soils are often found in layers, with each having a different chemical composition and texture

6. Water, which covers the majority of the earth's surface, circulates through the crust, oceans, and atmosphere in what is known as the "water cycle." Water evaporates from the earth's surface, rises and cools as it moves to higher elevation, condenses as rain or snow, and falls to the surface where it collects in lakes, oceans, soil, and in rocks underground

7. Water is a solvent. As it passes through the water cycle it dissolves minerals and gases and carries them to the oceans

(Table A-2 continued on next page) 
(Table A-2 continued)

\begin{tabular}{|c|c|}
\hline \multirow[t]{3}{*}{ NSES } & $\begin{array}{l}\text { 8. Living organisms have played many roles in the earth system, including affecting the composition of the } \\
\text { atmosphere, producing some types of rocks, and contributing to the weathering of rocks }\end{array}$ \\
\hline & $\begin{array}{l}\text { 9. The earth processes we see today, including erosion, movement of lithospheric plates, and changes in atmospheric } \\
\text { composition, are similar to those that occurred in the past. Earth history is also influenced by occasional } \\
\text { catastrophes, such as the impact of an asteroid or comet }\end{array}$ \\
\hline & 10. Fossils provide important evidence of how life and environmental conditions have changed \\
\hline \multirow[t]{9}{*}{ NGSS } & $\begin{array}{l}\text { 1. The geologic time scale interpreted from rock strata provides a way to organize Earth's history. Analyses of rock } \\
\text { strata and the fossil record provide only relative dates, not an absolute scale }\end{array}$ \\
\hline & 2. Tectonic processes continually generate new ocean sea floor at ridges and destroy old sea floor at trenches \\
\hline & $\begin{array}{l}\text { 3. All Earth processes are the result of energy flowing and matter cycling within and among the planet's systems. This } \\
\text { energy is derived from the sun and Earth's hot interior. The energy that flows and matter that cycles produce } \\
\text { chemical and physical changes in Earth's materials and living organisms }\end{array}$ \\
\hline & $\begin{array}{l}\text { 4. The planet's systems interact over scales that range from microscopic to global in size, and they operate over } \\
\text { fractions of a second to billions of years. These interactions have shaped Earth's history and will determine its } \\
\text { future }\end{array}$ \\
\hline & $\begin{array}{l}\text { 5. Maps of ancient land and water patterns, based on investigations of rocks and fossils, make clear how Earth's plates } \\
\text { have moved great distances, collided, and spread apart }\end{array}$ \\
\hline & $\begin{array}{l}\text { 6. Water continually cycles among land, ocean, and atmosphere via transpiration, evaporation, condensation and } \\
\text { crystallization, and precipitation, as well as downhill flows on land }\end{array}$ \\
\hline & $\begin{array}{l}\text { 7. Water's movements-both on the land and underground-cause weathering and erosion, which change the land's } \\
\text { surface features and create underground formations }\end{array}$ \\
\hline & $\begin{array}{l}\text { 8. Humans depend on Earth's land, ocean, atmosphere, and biosphere for many different resources. Minerals, fresh } \\
\text { water, and biosphere resources are limited, and many are not renewable or replaceable over human lifetimes. These } \\
\text { resources are distributed unevenly around the planet as a result of past geologic processes }\end{array}$ \\
\hline & $\begin{array}{l}\text { 9. Mapping the history of natural hazards in a region, combined with an understanding of related geologic forces can } \\
\text { help forecast the locations and likelihoods of future events }\end{array}$ \\
\hline
\end{tabular}

Table A-3. AAAS, NSES, NGSS Ages 14-13 (Grades 9-12).

\begin{tabular}{|c|c|}
\hline \multirow[t]{4}{*}{ AAAS } & $\begin{array}{l}\text { 1. The formation, weathering, sedimentation, and reformation of rock constitute a continuing "rock cycle" in which } \\
\text { the total amount of material stays the same as its forms change }\end{array}$ \\
\hline & $\begin{array}{l}\text { 2. The outward transfer of the earth's internal heat causes regions of different temperatures and densities. The action } \\
\text { of a gravitational force on regions of different densities causes the rise and fall of material between the earth's } \\
\text { surface and interior, which is responsible for the movement of plates }\end{array}$ \\
\hline & $\begin{array}{l}\text { 3. Earthquakes often occur along the boundaries between colliding plates, and molten rock from below creates } \\
\text { pressure that is released by volcanic eruptions, helping to build up mountains. Under the ocean basins, molten rock } \\
\text { may well up between separating plates to create new ocean floor. Volcanic activity along the ocean floor may form } \\
\text { undersea mountains, which can thrust above the ocean's surface to become islands }\end{array}$ \\
\hline & $\begin{array}{l}\text { The earth has many natural resources of great importance to human life. Some are readily renewable, some are } \\
\text { renewable only at great cost, and some are not renewable at all }\end{array}$ \\
\hline \multirow[t]{4}{*}{ NSES } & $\begin{array}{l}\text { 1. Earth systems have internal and external sources of energy, both of which create heat. The sun is the major external } \\
\text { source of energy. Two primary sources of internal energy are the decay of radioactive isotopes and the gravitational } \\
\text { energy from the earth's original formation }\end{array}$ \\
\hline & $\begin{array}{l}\text { 2. The outward transfer of earth's internal heat drives convection circulation in the mantle that propels the plates } \\
\text { comprising earth's surface across the face of the globe }\end{array}$ \\
\hline & $\begin{array}{l}\text { 3. The earth is a system containing essentially a fixed amount of each stable chemical atom or element. Each element } \\
\text { can exist in several different chemical reservoirs. Each element on earth moves among reservoirs in the solid earth, } \\
\text { oceans, atmosphere, and organisms as part of geochemical cycles }\end{array}$ \\
\hline & $\begin{array}{l}\text { 4. Movement of matter between reservoirs is driven by the earth's internal and external sources of energy. These } \\
\text { movements are often accompanied by a change in the physical and chemical properties of the matter. Carbon, for } \\
\text { example, occurs in carbonate rocks such as limestone, in the atmosphere as carbon dioxide gas, in water as } \\
\text { dissolved carbon dioxide, and in all organisms as complex molecules that control the chemistry of life }\end{array}$ \\
\hline
\end{tabular}

(Table A-3 continued on next page) 
(Table A-3 continued)

5. Geologic time can be estimated by observing rock sequences and using fossils to correlate the sequences at various locations. Current methods include using the known decay rates of radioactive isotopes present in rocks to measure the time since the rock was formed

6. Interactions among the solid earth, the oceans, the atmosphere, and organisms have resulted in the ongoing evolution of the earth system. We can observe some changes such as earthquakes and volcanic eruptions on a human time scale, but many processes such as mountain building and plate movements take place over hundreds of millions of years

NGSS 1. Continental rocks, which can be older than 4 billion years, are generally much older than the rocks of the ocean floor, which are less than 200 million years old

2. Although active geologic processes, such as plate tectonics and erosion, have destroyed or altered most of the very early rock record on Earth, other objects in the solar system, such as lunar rocks, asteroids, and meteorites, have changed little over billions of y ears. Studying these objects can provide information about Earth's formation and early history

3. Plate tectonics is the unifying theory that explains the past and current movements of the rocks at Earth's surface and provides a framework for understanding its geologic history

4. Spontaneous radioactive decays follow a characteristic exponential decay law. Nuclear lifetimes allow radiometric dating to be used to determine the ages of rocks and other material

5. Earth's systems, being dynamic and interacting, cause feedback effects that can increase or decrease the original changes

6. Evidence from deep probes and seismic waves, reconstructions of historical changes in Earth's surface and its magnetic field, and an understanding of physical and chemical processes lead to a model of Earth with a hot but solid inner core, a liquid outer core, a solid mantle and crust. Motions of the mantle and its plates occur primarily through thermal convection, which involves the cycling of matter due to the outward flow of energy from Earth's interior and gravitational movement of denser materials toward the interior

7. The geological record shows that changes to global and regional climate can be caused by interactions among changes in the sun's energy output or Earth's orbit, tectonic events, ocean circulation, volcanic activity, glaciers, vegetation, and human activities. These changes can occur on a variety of time scales from sudden (e.g., volcanic ash clouds) to intermediate (ice ages) to very long-term tectonic cycles

8. The radioactive decay of unstable isotopes continually generates new energy within Earth's crust and mantle, providing the primary source of the heat that drives mantle convection. Plate tectonics can be viewed as the surface expression of mantle convection

9. Plate tectonics is the unifying theory that explains the past and current movements of the rocks at Earth's surface and provides a framework for understanding its geologic history. Plate movements are responsible for most continental and ocean-floor features and for the distribution of most rocks and minerals within Earth's crust

10. The abundance of liquid water on Earth's surface and its unique combination of physical and chemical properties are central to the planet's dynamics. These properties include water's exceptional capacity to absorb, store, and release large amounts of energy, transmit sunlight, expand upon freezing, dissolve and transport materials, and lower the viscosities and melting points of rocks

11. The many dynamic and delicate feedbacks between the biosphere and other Earth systems cause a continual coevolution of Earth's surface and the life that exists on it

12. Geologists use seismic waves and their reflection at interface between layers to probe structures deep in the planet

13. All forms of energy production and other resource extraction have associated economic, social, environmental, and geopolitical costs and risks as well as benefits. New technologies and social regulations can change the balance of these factors.

14. Natural hazards and other geologic events have shaped the course of human history; [they] have significantly altered the sizes of human populations and have driven human migrations

Notes: This table displays the AAAS, NSES, and NGSS for students between ages 14-18 (Grades 9-12). 
Table A-4. ESLP Standards.

Big Idea 1. Earth Scientists use repeatable observations and testable ideas to understand and explain our planet 1.1 Earth scientists find solutions to society's needs: Earth scientists work on challenging problems that face humanity on topics such as climate change and human impacts on Earth. Earth scientists successfully predict hazards to humans and locate and recover natural resources, making possible the flourishing of humans on Earth

1.2 Earth scientists use a large variety of scientific principles to understand how our planet works: Earth scientists combine study of Earth's geology with aspects of biology, chemistry, physics, and mathematics in order to understand the complexities of the Earth system

1.3 Earth science investigations takes many different forms: Earth scientists do reproducible experiments and collect multiple lines of evidence. This evidence is taken from field, analytical, theoretical, experimental, and modeling studies

1.4 Earth scientists must use indirect methods to examine and understand the structure, composition, and dynamics of Earth's interior: With the exception of wells and mineshafts drilled into Earth, direct observations of Earth's interior are not possible. Instead, Earth scientists observe the interior of the planet using seismic waves, gravity, magnetic fields, radar, sonar, and laboratory experiments on the behavior of materials at high pressures and temperatures

1.5 Earth scientists use their understanding of the past to forecast Earth's future: Earth science research tells us how Earth functioned in the past under conditions not seen today and how conditions are likely to change in the future

1.6 Earth scientists construct models of Earth and its processes that best explain the available geological evidence: These scientific models, which can be conceptual or analytical, undergo rigorous scrutiny and testing by collaborating and competing groups of scientists around the world. Earth science research documents are subjected to rigorous peer review before they are published in science journals

1.7 Technological advances, breakthroughs in interpretation, and new observations continuously refine our understanding of Earth: This Earth Science Literacy frame- work must be a living document that grows along with our changing ideas and concepts of Earth

\section{Big Idea 2. Earth is 4.6 billion years old}

2.1 Earth's rocks and other materials provide a record of its history: Earth scientists use the structure, sequence, and properties of rocks, sediments, and fossils to reconstruct events in Earth's history. Decay rates of radioactive elements are the primary means of obtaining numerical ages of rocks and organic remains. Understanding geologic processes active in the modern world is crucial to interpreting Earth's past

2.2 Our Solar System formed from a vast cloud of gas and dust 4.6 billion years ago: Some of this gas and dust was the remains of the supernova explosion of a previous star; our bodies are therefore made of "stardust." This age of 4.6 billion years is well established from the decay rates of radioactive elements found in meteorites and rocks from the Moon 2.3 Earth formed from the accumulation of dust and gas, and multiple collisions of smaller planetary bodies: Driven by gravity, Earth's metallic core formed as iron sank to the center. rock surrounding the core was mostly molten early in Earth's history, and slowly cooled to form Earth's mantle and crust. The atoms of different elements combined to make minerals, which combined to make rocks. Earth's ocean and atmosphere began to form more than 4 billion years ago from the rise of lighter materials out of the mantle

2.4 Earth's crust has two distinct types: continental and oceanic: Continental crust persists at Earth's surface and can be billions of years old. Oceanic crust continuously forms and recycles back into the mantle; in the ocean, it is nowhere older than about 200 million years

2.5 Studying other objects in the solar system helps us learn Earth's history: Active geologic processes such as plate tectonics and erosion have destroyed or altered most of Earth's early rock record. Many aspects of Earth's early history are revealed by objects in the solar system that have not changed as must as Earth has

2.6 Life on Earth began more than 3.5 billion years ago: Fossils indicate that life began with single-celled organisms, which were the only life forms for billions of years. Humans (homo sapiens) have existed for only a very small fraction $(0.004 \%)$ of Earth's history

2.7 Over Earth's vast history, both gradual and catastrophic processes have produced enormous change: Super-continents formed and broke apart, the compositions of the atmosphere and ocean changed, sea level rose and fell, living species evolved and went extinct, ice sheets advanced and melted away, meteorites slammed into Earth, and mountains formed and eroded away 


\begin{abstract}
Big Idea 3. Earth is a complex system of interacting rock, water, air, and life
3.1 The four major systems of Earth are the geosphere, hydrosphere, atmosphere, and biosphere: The geosphere includes a metallic core, solid and molten rock, soil and sediments. The atmosphere is the envelope of gas surrounding Earth. The hydrosphere includes the ice, water vapor, and liquid water in the atmosphere, the ocean, lakes, streams, soils, and ground water. The biosphere includes Earth's life, which can be found in many parts of the geosphere, hydrosphere, and atmosphere. Humans are part of the biosphere, and human activities have impacts on all four spheres

3.2 All Earth processes are the result of energy flowing and mass cycling within and between Earth's systems: This energy is derived from the sun and Earth's interior. The flowing energy and cycling matter cause chemical and physical changes in Earth's materials and living organisms. For example, large amounts of carbon continually cycle among systems of rock, water,
\end{abstract} air, organisms, and fossil fuels such as coal and oil

3.3 Earth exchanges mass and energy with the rest of the Solar System: Earth gains and loses energy through incoming solar radiation, heat loss to space, and gravitational forces from the sun, moon, and planets. Earth gains mass from the impacts of meteoroids and comets and loses mass by the escape of gases into space

3.4 Earth's systems interact over a wide range of temporal and spatial scales: These scales range from microscopic to global in size and operate over fractions of a second to billions of years. These interactions among Earth's systems have shaped Earth's history and will determine Earth's future

3.5 Regions where organisms actively interact with each other and their environment are called ecosystems: Ecosystems provide the goods (food, fuel, oxygen, and nutrients) and services (climate regulation, water cycling and purification, and soil development and maintenance) necessary to sustain the biosphere. Ecosystems are considered the planet's essential lifesupport units

3.6 Earth's systems are dynamic; they continually react to changing influences: Components of Earth's systems may appear stable, change slowly over long periods of time, or change abruptly with significant consequences for living organisms

3.7 Changes in part of one system can cause new changes to that system or to other systems, often in surprising and complex ways: These new changes may take the form of "feedbacks" that can increase or decrease the original changes and can be unpredictable and/or irreversible. A deep knowledge of how most feedbacks work within and between Earth's systems is still lacking

3.8 Earth's climate is an example of how complex interactions among systems can result in relatively sudden and significant changes: The geologic record shows that interactions among tectonic events, solar inputs, planetary orbits, ocean circulation, volcanic activity, glaciers, vegetation, and human activities can cause appreciable, and in some cases rapid, changes to global and regional patterns of temperature and precipitation

Big Idea 4. Earth is continuously changing

4.1 Earth's geosphere changes through geological, hydrological, physical, chemical, and biological processes that are explained by universal laws: These changes can be small or large, continuous or sporadic, and gradual or catastrophic

4.2 Earth, like other planets, is still cooling through radioactive decay continuously generates internal heat: This heat flows through and out of Earth's interior largely through convection, but also through conduction and radiation. The flow of Earth's heat is like its lifeblood, driving its internal motions

4.3 Earth's interior is in constant motion through the process of convection, with important consequences for the surface: Convection is the iron-rich liquid outer core, along with Earth's rotation around its axis, generates Earth's magnetic field. By deflecting solar wind around the planet, the magnetic field prevents the solar wind from stripping away Earth's atmosphere. Convection in the solid mantle drives the many processes of plate tectonics, including the formation and movements of the continents and oceanic crust

4.4 Earth's tectonic plates consist of the rocky crust and uppermost mantle, and move slowly with respect to one another: New oceanic plate continuously forms at mid-ocean ridges and other spreading centers, sinking back into the mantle at ocean trenches. Tectonic plates move steadily at rates of up to 10 centimeters per year

4.5 Many active geologic processes occur at plate boundaries: Plate interactions change the shapes, sizes, and positions of continents and ocean basins, the locations of mountain ranges and basins, the patterns of ocean circulation and climate, the locations of earthquakes and volcanoes, and the distribution of resources and living organisms

4.6 Earth materials take many different forms as they cycle through the geosphere: Rocks form from the cooling of magma, the accumulation and consolidation of sediments, and the alteration of older rocks by heat, pressure, and fluids. These three processes form igneous, sedimentary, and metamorphic rocks

4.7 Landscapes result from the dynamic interplay between processes that form and uplift new crust and processes that destroy and depress the crust: This interplay is affected by gravity, density differences, plate tectonics, climate, water, the actions of living organisms, and the resistance of Earth materials to weathering and erosion

4.8 Weathered and unstable rock materials erode from some parts of Earth's surface and are deposited in others: Under the influence of gravity, rocks fall downhill. Water, ice, and air carry eroded sediments to lower elevations, and ultimately to the ocean

4.9 Shorelines move back and forth across continents, depositing sediments that become the surface rocks of the land: Through dynamic processes of plate tectonics and glaciation, Earth's sea level rises and falls by up to hundreds of meters. This fluctuation causes shorelines to advance and recede by hundreds of kilometers. The upper rock layers of most continents formed when rising sea levels repeatedly flooded the interiors of continents

(TableA-4 continued on next page) 
(Table A-4 continued)

\begin{abstract}
Big Idea 5. Earth is the water planet
5.1 Water is found everywhere on Earth, from the heights of the atmosphere to the depths of the mantle: Early in Earth's history, surface water accumulated through both outgassing from its interior and the capture of some extraterrestrial ice. Water vapor in the atmosphere condensed and rained out as a planet cooled

5.2 Water is essential for life on Earth: Earth is unique in our Solar Systems in that water has coexisted at Earth's surface in three phases (solid, liquid, and gas) for billions of years, allowing the development and continuous evolution of life

5.3 Water's unique combination of physical and chemical properties are essential to the dynamics of all Earth's systems: These properties include the manner in which water absorbs and releases heat, reflects sunlight, expands upon freezing, and dissolves other materials

5.4 Water plays an important role in many of Earth's deep internal processes: Water allows rock to melt more easily, generating much of the magma that erupts as lava at volcanoes. Water facilitates the metamorphic alteration of rock and is integral to plate tectonic processes

5.5 Earth's water cycles among the reservoirs of the atmosphere, streams, lakes, ocean, glaciers, groundwater, and deep interior of the planet: The total amount of water at Earth's surface has remained fairly constant over geologic time, although it distribution among reservoirs has varied

5.6 Water shapes landscapes: Flowing water in streams strongly shapes the land surface through weathering, erosion, transport, and deposition. Water participates in both the dissolution and formation of Earth's materials

5.7 Ice is an especially powerful agent of weathering and erosion: Water expands as it freezes, widening cracks and breaking apart rocks. Movement of massive glaciers can scour away land surfaces. The flowing ice of glaciers covers and alters vase areas of continents during Ice Ages

5.8 Fresh water is less than 3\% of the water at Earth's surface: Most of this freshwater is stored as glaciers in Antarctica and Greenland. Less than $1 \%$ of Earth's near surface water is drinkable liquid fresh water, and about $99 \%$ of this water is in the form of groundwater in the pores and fractures within soil, sediment, and rock
\end{abstract}

\title{
Big Idea 6. Life evolves on a dynamic Earth and continuously modifies Earth
}

6.1 Fossils are the preserved evidence of ancient life: Fossils document the presence of life early in Earth's history and the subsequent evolution of life over billions of years

6.2 Evolution, including the origination and extinction of species, is a natural and ongoing process: Changes to Earth and its ecosystems determine which individuals, populations, and species survive. As an outcome of dynamic Earth processes, life has adapted through evolution to new, diverse, and ever-changing niches

6.3 Biological diversity, both past and present, is vast and largely undiscovered: New species of living and fossil organisms are continually found and identified. All of this diversity is interrelated through evolution

6.4 More complex life forms and ecosystems have arisen over the course of Earth's history: This complexity has emerged in association with adaptions to new and constantly changing habits. But not all evolution causes greater complexity; organisms adapting to changing local environments may also become simpler

6.5 Microorganisms dominated Earth's early biosphere and continue today to be the most widespread, abundant, and diverse group of organisms on the planet: Microbes change the chemistry of Earth's surface and play critical role in nutrient cycling within most ecosystems

6.6 Mass extinctions occur when global conditions change faster than species in large numbers can adapt: Mass extinctions are often followed by the origination of many new species over millions of years as surviving species evolve and fill vacated niches

6.7 The particular life forms that exist today, including humans, are a unique result of the history of Earth's systems: Had this history been slightly different, modern life forms might be entirely different and human might never have evolved

6.8 Life changes the physical and chemical properties of Earth's geosphere, hydrosphere, and atmosphere: Living organisms produced most of the oxygen in the atmosphere through photosynthesis and provided the substance of fossil fuels and many sedimentary rocks. The fossil record provides a means for understanding the history of these changes

6.9 Life occupies a wide range of Earth's environments, including extreme environments: Some microbes live in rocks kilometers beneath the surface, within glacial ice, and at seafloor vents where hot fluids escape from the oceanic crust. Some of these environments may be similar to the conditions under which life originated, and to environments that exist on other planets and moons

(Table A-4 continued on next page) 
(Table A-4 continued)

\begin{abstract}
Big Idea 7. Humans depend on Earth for resources
7.1 Earth is our home; its resources mold civilizations, drive human exploration, and inspire human endeavors that include art, literature, and science: We depend upon Earth for sustenance, comfort, places to live and play, and spiritual inspiration 7.2 Geology affects the distribution and development of human population: Human population have historically concentrated at sites that are geologically advantageous to commerce, food production, and other aspects of civilization 7.3 Natural resources are limited: Earth's natural resources provide the foundation for all of human society's physical needs. Most are nonrenewable on human time scales, and many will run critically low in the near future

7.4 Resources are distributed unevenly around the planet: Resources distribution is a result of how and where geologic processes have occurred in the past, and has extremely important social, economic, and political implication

7.5 Water resources are essential for agriculture, manufacturing, energy production, and life: Earth scientists and engineers find and manage our freshwater resources, which are limited in supply. In many places, humans withdraw both surface water and groundwater faster than they are replenished. Once fresh water is contaminated, its quality is difficult to restore

7.6 Soil, rocks, and minerals provide essential metals and other materials for agriculture, manufacturing, and building: Soil develops slowly from weathered rock, and the erosion of soil threatens agriculture. Minerals and metals are often concentrated in very specific ore deposits. Locating and mining these ore deposits provide the raw materials for much of our industry. Many electronic and mechanical devices have specific requirements for particular rare metals and minerals that are short in supply

7.7 Earth scientists and engineers develop new technologies to extract resources while reducing the pollution, waste, and ecosystem degradation caused by extraction: For example, land reclamation can partially restore surface environments following surface mining

7.8 Oil and natural gas are unique resources that are central to modern life in many different ways: They are the precursors to chemicals used to make numerous products, such as plastics, textiles, medications, and fertilizers. Petroleum sources are needed to manufacture most industrial products

7.9 Fossil fuels and uranium currently provide most of our energy resources: Fossil fuels, such as coal, oil, and natural gas, take tens to hundreds of millions of years to form. Their abundance will make them the dominant source of energy for the near future. New sources, such as methane hydrates, are being explored

7.10 Earth scientists help society move toward greater sustainability: Renewable energy sources, such as solar, wind, hydroelectric, and geothermal, are being developed. They will replace fossil fuels as those become scarcer, more expensive to retrieve from Earth, and undesirable due to environmental damage. Earth scientists foster global cooperation and scienceinformed stewardship that can help to ensure the availability of resources for future generations
\end{abstract}

Big Idea 8. Natural hazards pose risks to humans

8.1 Natural hazards result from natural Earth processes: These hazards include earthquakes, tsunamis, hurricanes, floods, droughts, landslides, volcanic eruptions, extreme weather, lightning-induced fires, sinkholes, coastal erosion, and comet and asteroid impacts

8.2 Natural hazards shape the history of human societies: Hazardous events can significantly alter the size of human populations and drive human migrations. Risks from natural hazards increase as populations expand into vulnerable areas or concentrate in already-inhabited areas

8.3 Human activities can contribute to the frequency and intensity of some natural hazards: These hazards include floods, landslides, droughts, forest fires, and erosion

8.4 Hazardous events can be sudden or gradual: They range from sudden events such as earthquakes and explosive volcanic eruptions, to more gradual phenomena such as droughts, which may last decades or longer. Changes caused by continual processes such as erosion and land subsidence can also result in risks to human populations, as with the increased risk of flooding in New Orleans

8.5 Natural hazards can be local or global in origin: Local events can have distant impacts because of the interconnectedness of both human societies and Earth's systems. For example, a volcanic eruption in the Pacific Ocean can impact climate around the globe

8.6 Earth scientists are continually improving estimates of when and where natural hazards occur: This analysis is done through continuously monitoring Earth, increasing our understanding of the physical processes that underlie its changes, and developing scientific models that can explain hazard-related scientific observations

8.7 Humans cannot eliminate natural hazards, but can engage in activities that reduce their impacts: Loss of life, property damage, and economic costs can be reduced by identifying high-risk locations and minimizing human habitation and societal activities in them, improving construction methods, developing warning systems, and recognizing how human behavior influences preparedness and response

8.8 An Earth-science-literate public is essential for reducing risks from natural hazards: This literacy leads to the promotion of community awareness about natural hazards and to the development of scientifically informed policies that reduce risk

(Table A-4 continued on next page) 
(Table A-4 continued)

\begin{tabular}{l} 
Big Idea 9. Humans significantly alter the Earth \\
\hline 9.1 Human activities significantly change the rates of many of Earth's surface processes: Humankind has become a geological \\
agent that must be taken into account equally with natural processes in any attempt to understand the workings of Earth's \\
systems. As human populations and per capita consumption of natural resources increase, so do our impacts on Earth's \\
systems \\
9.2 Earth scientists use the geologic record to distinguish between natural and human influences on Earth's systems: Evidence \\
for natural and human influences on Earth processes is found in ice cores and soils, and in lake, estuary, and ocean sediments \\
9.3 Humans cause global climate change through fossil fuel combustion, land-use changes, agricultural practices, and \\
industrial processes: Consequences of global climate change include melting glaciers and permafrost, rising sea levels, \\
shifting precipitation patterns, increased forest fires, more extreme weather, and the disruption of global ecosystems \\
9.4 Humans affect the quality, availability, and distribution of Earth's water through the modification of streams, lakes, and \\
groundwater: Engineered structures such as canals, dams, and levees significantly alter water and sediment distribution. \\
Pollution from sewage runoff, agricultural practices, and industrial processes reduce water quality. Overuse of water for \\
electric power generation and agriculture reduces water availability for drinking \\
9.5 Human activities alter the natural land surface: Humans use more than one-third of the land's surface not covered with ice \\
to raise or grow their food. Large areas of land, including delicate ecosystems such as wetlands, are transformed by human \\
land development. These land surface changes impact many Earth processes such as groundwater replenishment and weather \\
patterns
\end{tabular}

9.6 Human activities accelerate land erosion: At present, the rate of global land erosion caused by human activities exceeds all natural processes by a factor of ten. These activities include urban paving, removal of vegetation, surface mining, stream diversions, and increased rain acidity

9.7 Human activities significantly alter the biosphere: Earth is experiencing a worldwide decline in biodiversity-a modern mass extinction-due to loss of habitat area and high rates of environmental change caused by human activities. The rates of extinctions are now comparable to the rates of mass extinctions in the geologic past

9.8 Earth scientists document and seek to understand the impacts of humans on global change over short and long time spans: Many of these human impacts on Earth's systems are not reversible over human lifetimes, but through human cooperation their impacts on future generations can be lessened and even reversed 9.9 An Earth-science-literate public, informed by current and accurate scientific understanding of Earth, is critical to the promotion of good stewardship, sound policy, and international cooperation: Earth science education is important for individuals of all ages, backgrounds, and nationalities

Notes: The ESLP are listed in a table separate from AAAS, NSES, and NGSS because they are categorized by "Big Ideas" and not age and/or grade level. 